\title{
Las encuestas de opinión como reflejo de las preocupaciones reales de la ciudadanía vasca. El euskobarómetro frente al programa Euskadi pregunta
}

\author{
Susana PARDIÑAS IGLESIAS \\ Universidad Complutense de Madrid \\ spardina@ucm.es
}

\begin{abstract}
Resumen:
El objeto de este trabajo es analizar de forma objetiva y mediante un análisis cuantitativo, el grado de coincidencia existente entre las preocupaciones que, según el euskobarómetro, tienen los ciudadanos vascos, y las preguntas independientes que éstos hacen a los candidatos nacionalistas en el programa de EITB2 Euskadi pregunta.

Analizamos un período concreto como es el de la precampaña autonómica del año 2012, porque queremos comprobar si existe relación entre los temas que tienen mayor interés para la ciudadanía según la encuesta de opinión, y las preguntas que finalmente hacen a los candidatos políticos cuando tienen la oportunidad de plantearles sus dudas y preocupaciones en público antes de un proceso electoral.

Hemos seleccionado a los candidatos nacionalistas, Iñigo Urkullu y Laura Mintegi, para delimitar un poco las temáticas que los ciudadanos introducen en cada una de las cuestiones, y su intencionalidad, y así concretar más la investigación.

El Euskobarómetro que analizamos es el último anterior a las elecciones del 21 de octubre de 2012, concretamente el del mes de mayo. Se trata de un estudio de opinión pública y de comportamiento político realizado a los ciudadanos vascos. En este caso consta de una muestra de algo más de 1000 entrevistas realizadas a perfiles previamente definidos.

Las entrevistas, emitidas en directo a través de EITB2, tienen lugar los días 24 de septiembre, la de Laura Mintegi, y, a pocos días del inicio oficial de la campaña, el 4 de octubre, la de Iñigo Urkullu.
\end{abstract}

Palabras clave: Opinión; elecciones; vascas; encuestas; ciudadanos.

\section{Opinion polls reflecting the real concerns of Basque citizens. The Euskoba- rómetro against the Euskadi question Programme}

\begin{abstract}
:
The objective of this work is to analyze objectively and through a quantitative analysis the consciousness degree between the worries that the Basque citizens have and the questions that these ask to the nationalist candidates during the program EITB2 Euskady pregunta (says the Euskobarometro).

We analyze a specific period, this is the 2012 autonomic campaign, because we want to verify if there is any relation between the issues that are of most interest to the citizens, based on a poll, and the questions that they ask the candidates at the end when they have the opportunity of exposing their worries publicly. Our selected candidates are Iñigo Urkullu and Laura Mintegi, so that we can establish some limits on the subjects exposed on each question, their intentions, so that way we can be more specific on our investigation.
\end{abstract}


The Euskobarometro that we analysed is the last one from the elections of 21st of October of 2012, the one from May to be more specific. To be even more specific, we could say this is a study based on the people's opinion and political behaviour aimed for the Basque citizens. The sample in this case is a bit more than 1000 interviews with predefined profiles.

The interviews, showed live on EITB2, the one by Laura Mintegi take place on the 24th of September and a few days after, the 4th of October, the one by Iñigo Urkullu.

Key Words: Opinion; eleccions; basque; polls; citicens

\section{Referencia normalizada:}

Pardiñas Iglesias, S. (2014): Las encuestas de opinión como reflejo de las preocupaciones reales de la ciudadanía vasca. El euskobarómetro frente al programa Euzkadi pregunta. Historia y Comunicación Social. Vol. 19. Núm. Especial Marzo. Págs. 197-211.

Sumario: 1. Introducción, 2. Metodología, 3. Análisis del programa Euzkadi pregunta, 3.1 Euzkadi pregunta a Laura Mintegi, 3.2 Euzkadi pregunta a Iñigo Urkullu, 4. Análisis de los temas de interés de la ciudadanía vasca, 5. Conclusiones, 6. Bibliografía.

\section{Introducción}

La finalidad de esta investigación es analizar la existencia de correlación entre las preguntas realizadas por el público que participa en el programa de la televisión vasca EITB2 Euskadi pregunta a los candidatos nacionalistas Iñigo Urkullu (PNV) y Laura Mintegi (EH-Bildu), y los principales temas de preocupación de la ciudadanía recogidos en el Euskobarómetro.

El programa Euskadi pregunta se emite en el canal 2 de la televisión pública vasca (EITB) cuya lengua principal es el castellano. Se trata de un formato similar al popular Tengo una pregunta para usted que emitió la televisión pública española.

Se reúne a 30 ciudadanos vascos, seleccionados por una empresa externa, durante 90 minutos en plató y se les pide que, libremente, planteen una pregunta al candidato o candidata invitado en el estudio. Solamente pueden hacer una pregunta, no se permite el debate.

Los candidatos tienen 3 minutos para responder. Lo hacen de pié, mirando de frente al público. No hay descansos publicitarios, por lo que la sesión transcurre ininterrumpidamente a lo largo de los 90 minutos.

El programa está moderado por una periodista que en ocasiones introduce alguna pregunta que llega a través de internet -concretamente cinco- indicando siempre nombre y apellidos de la persona que la formula.

La moderadora, que en este caso es África Baeta, prácticamente no interviene y si lo hace, en contadas ocasiones, es para preguntar cómo se encuentran los participan- 
tes -público y entrevistado- o para hacer alguna pregunta más personal al candidato o candidata con el objetivo de destensar el ambiente.

Cada participante del público se pone de pié cada vez que formula una pregunta. Previamente la moderadora lo presenta diciendo su nombre y apellidos, edad y profesión.

Llevan unas tarjetas con las cuestiones que plantean por si con los nervios del momento olvidan la pregunta. El programa insiste en que se trata de pregunta redactadas por los propios ciudadanos, no hay ninguna intervención externa y los entrevistados no las conocen previamente.

\section{Metodología}

Para el análisis propuesto en este trabajo se han estudiado las 35 preguntas realizadas a Iñigo Urkullu, que asiste el programa el 4 de octubre de 2012, y las 35 formuladas a Laura Mintegi, que participa el 24 de septiembre de 2012.

Se comparan con las principales preocupaciones de la ciudadanía vasca recogidas en el Euskobarómetro de mayo de 2012, que sería el último antes de las elecciones autonómicas.

Partimos de la definición de Bosch y Torrente que recoge Igartua (Igartua, 2006: 136) y que definen una encuesta como "el conjunto de procesos encaminados a obtener una determinada información de una muestra representativa de una población, mediante un conjunto de preguntas"

El Euskobarómetro es un estudio de opinión pública y de comportamiento político realizado a los ciudadanos vascos. Lo realiza un equipo de investigación de la Universidad del País Vasco, y goza de cada vez mayor prestigio por su calidad científica.

Analiza la situación y preocupaciones personales, clima social y económico, malestar democrático y confianza institucional; el clima y evaluación política y gubernamental y liderazgo político; el sentimiento nacionalista e identidad vasca, autogobierno y actitud ante la independencia; y la evolución de la violencia y actitudes antes la misma, el final del terrorismo y la normalización política.

En esta ocasión consta de 1.200 entrevistas realizadas entre los días 8 y 24 de mayo de 2012.

He optado por dividir los temas de preocupación de la ciudadanía vasca siguiendo este sondeo en seis apartados:

- El empleo o desempleo

- La crisis

- Las desigualdades sociales y el bienestar 
- La situación política

- La vivienda

- La violencia

El objetivo es comprobar si existe coincidencia entre estos temas y los planteados en el programa, para determinar si realmente la ciudadanía se atreve a exponer sus preocupaciones reales a los políticos, y si el programa recoge la realidad social de la ciudadanía vasca.

\section{Análisis del programa Euzkadi Pregunta}

\subsection{Euzkadi pregunta a Laura Mintegi}

El 24 de septiembre el programa invita a Laura Mintegi a responder a las cuestiones que le plantean los ciudadanos. Responde a las 35 preguntas, pero se aprecia cierto nerviosismo o falta de concentración de la candidata que en ocasiones duda al responder.

Llama la atención que no utiliza datos para apoyar sus afirmaciones lo que le quita consistencia y fuerza al discurso. Repite sistemáticamente su postura sobre cuestiones que considera inadmisibles o "impúdicas y obscenas" como dice literalmente al referirse al rescate de la banca o la renta vitalicia de los presidentes.

Su gesto facial transmite tranquilidad y los gestos de sus manos son suaves, incluso cuando se coloca el cabello, gesto que hace en varias ocasiones.

Está de pie mirando de frente al público y sonríe suavemente ante cada pregunta, incluso ante las más duras.

Su tono de voz también transmite mucha calma, y aunque lo modula poniendo énfasis en determinadas palabras, no levanta el tono ni cuando habla de temas que le gustan menos o situaciones que critica.

Otro aspecto que resulta relevante es que cuando le preguntan cómo se siente o qué le han parecido las preguntas que le hace el público ella plantea que le gustaría más saber qué les han parecido las respuestas que ha dado, si cumplen las expectativas o esperaban algo más de ella.

Transmite la sensación de que es una mujer tranquila y pacífica, con un gran control de su comunicación gestual.

Eso choca en ocasiones con sus respuestas que son bastante largas, muchas veces divaga porque no se la ve segura.

Le formulan 35 preguntas (ver tabla 1): 


\section{Tabla 1}

\begin{tabular}{|c|c|c|}
\hline \multicolumn{2}{|r|}{ PREGUNTA } & \multirow{2}{*}{$\begin{array}{l}\text { TEMA } \\
\text { Crisis e } \\
\text { independencia }\end{array}$} \\
\hline & $\begin{array}{l}\text { Los estados del bienestar más desarrollados como Suecia } \\
\text { o Dinamarca han sido siempre muy abiertos a la } \\
\text { economía internacional y fuertemente internacionales aún } \\
\text { a pesar de ser estados muy pequeños. ¿No hay una } \\
\text { contradicción entre un proyecto nacionalista y la } \\
\text { intención de crear un estado del bienestar? }\end{array}$ & \\
\hline 2) & $\begin{array}{l}\text { Sin olvidarme de otro tipo de víctimas, como fueron las } \\
\text { del GAL o las de los excesos policiales que hubieran } \\
\text { podido producirse, acciones todas ellas condenables y } \\
\text { graves, yo le centraría mi pregunta en unos damnificados } \\
\text { muy concretos, en las víctimas de ETA. Es un hecho que } \\
\text { la izquierda abertzale nunca estuvo a su lado, y donde } \\
\text { ETA recibió probablemente cierto calor, sus víctimas } \\
\text { solo recibieron indiferencia, le ruego por favor evitar los } \\
\text { juegos de palabras en la medida de lo posible, ¿sienten } \\
\text { que hicieron algo mal ustedes? ¿se sienten ustedes } \\
\text { responsables por haber mirado en cierto momento hacia } \\
\text { otro lado, hasta el punto de llevar a cabo si gobiernan } \\
\text { medidas concretas para reconocerlas y para intentar } \\
\text { reparar ese dolor y el de sus familias evidentemente } \\
\text { también? }\end{array}$ & ETA \\
\hline 3) & $\begin{array}{l}\text { Mi pregunta es sobre el transporte público, ese que los } \\
\text { políticos usan más bien poco y es bueno en referencia a } \\
\text { otras ciudades del territorio, en principio nadie o muy } \\
\text { poca gente apostaba por el metro. Luego parece que su } \\
\text { uso en esas ciudades ha sido mayoritario. ¿Qué le parece } \\
\text { el proyecto de metro en San Sebastián, que barrios como } \\
\text { Intxaurrondo, como Alza y ciudades como Ondarribia } \\
\text { puedan tener este servicio? ¿Ve usted factible este } \\
\text { proyecto de metro para Donosti? }\end{array}$ & Transporte \\
\hline 4) & Dado el estado de la economía, ¿con quién pactaría? & Pacto político \\
\hline 5) & $\begin{array}{l}\text { Si llega a lehendakari, ¿cuál sería su política de } \\
\text { inmigración? }\end{array}$ & Inmigración \\
\hline 6) & $\begin{array}{l}\text { INTERNET: ¿Defiende usted el sistema puerta a puerta } \\
\text { de recogida de basuras para toda Euskadi, o solo para } \\
\text { algunos pueblos de Guipuzkoa? ¿Por qué si es bueno para } \\
\text { Oyarzun no es los mismo para Zarautz? }\end{array}$ & Reciclaje \\
\hline 7) & $\begin{array}{l}\text { Los y las jóvenes hoy en día tenemos muy difícil } \\
\text { emanciparnos, cada vez tenemos trabajos más precarios y } \\
\text { sueldos más bajos si es que los tenemos. La vivienda es } \\
\text { algo inalcanzable bien sea de compra o en alquiler, y en } \\
\text { algunos municipios como en Bilbao la oferta de viviendas } \\
\text { de VPO es muy baja y no satisface las necesidades de la } \\
\text { ciudadanía. Euskal Herría Bildu. ¿Qué propuesta tiene } \\
\text { antes este problema o qué solución ve? }\end{array}$ & Crisis y vivienda \\
\hline 8) & $\begin{array}{l}\text { Hemos visto como la deuda de la banca privada se ha } \\
\text { socializado convirtiéndola en deuda pública para que la } \\
\text { paguemos entre todos. ¿Crees que esta deuda privada y } \\
\text { otras derivadas pues del despilfarro, la mala gestión y la } \\
\text { corrupción debe ser objeto de una moratoria, una } \\
\text { auditoria ciudadana y en su caso de una quita, es decir no }\end{array}$ & Crisis y banca \\
\hline
\end{tabular}




\begin{tabular}{|c|c|c|}
\hline & $\begin{array}{l}\text { pagamos vuestra deuda, y si es así qué métodos puedes } \\
\text { proponer para ello? }\end{array}$ & \\
\hline 9) & $\begin{array}{l}\text { Mi pregunta va relacionada con los museos. ¿Va a apoyar } \\
\text { a los museos de localidades pequeñas que tienen un valor } \\
\text { y un interés etnográfico reconocidos como es el propio } \\
\text { etnográfico de Artziniega? }\end{array}$ & Cultura \\
\hline 10) & $\begin{array}{l}\text { ¿Requerirá de manera urgente la caja propia de la } \\
\text { seguridad social para Euskadi? }\end{array}$ & Independencia \\
\hline & $\begin{array}{l}\text { Debido a la crisis me gustaría saber ¿qué política van a } \\
\text { seguir en su partido en referencia a la investigación, en } \\
\text { concreto en las universidades, es decir cómo van a afectar } \\
\text { estos recortes a la investigación en concreto? }\end{array}$ & Crisis y educación \\
\hline & $\begin{array}{l}\text { INTERNET: ¿Si gana las elecciones quién será el } \\
\text { consejero de infraestructuras y transportes, qué política } \\
\text { desarrollarán en esa área y sobre todo qué decisión } \\
\text { tomarán con respecto a las obras del tren de alta } \\
\text { velocidad? }\end{array}$ & $\begin{array}{l}\text { Crisis y alta } \\
\text { velocidad }\end{array}$ \\
\hline & $\begin{array}{l}\text { ¿Estaría dispuesta usted y su coalición electoral a redactar } \\
\text { un código ético deontológico propio de obligado } \\
\text { cumplimiento para los cargos electos difundiendo su } \\
\text { edición junto a su programa electoral. Un código que } \\
\text { busque recuperar los valores que todo representante } \\
\text { electo debería tener y mantener durante todo el periodo } \\
\text { de ejercicio de poder y responsabilidad otorgado por la } \\
\text { ciudadanía? }\end{array}$ & Ética y políticos \\
\hline & $\begin{array}{l}\text { Después de comentar usted la conveniencia de que el } \\
\text { Athletic Club de Bilbao aporte parte de lo cobrado por el } \\
\text { jugador Javi Martínez y destinar el dinero público para } \\
\text { otras prioridades, ¿qué opinión le merece el hecho de que } \\
\text { el ayto de Donosti aporte el dinero para el estadio de } \\
\text { Anoeta eliminando la pista de atletismo para uso } \\
\text { exclusivo de un club privado y con deudas a la Seguridad } \\
\text { Social? }\end{array}$ & $\begin{array}{l}\text { Crisis e inversión } \\
\text { pública }\end{array}$ \\
\hline & $\begin{array}{l}\text { ¿Cuál piensa usted qué es el motivo para que en un país } \\
\text { del primer mundo como este hoy en día exista pobreza. Y } \\
\text { qué se podría hacer para evitar la situación precaria actual } \\
\text { que sufren tantas personas en el País Vasco? }\end{array}$ & Crisis \\
\hline & $\begin{array}{l}\text { ¿Después de las próximas elecciones, ganéis o no ganéis, } \\
\text { es vuestra intención gestionar con matices el sistema } \\
\text { neoliberal capitalista o adoptareis otras vías para construir } \\
\text { un mundo no capitalista? }\end{array}$ & Sistema político \\
\hline & $\begin{array}{l}\text { ¿Mantendría usted la tarjeta sanitaria a parados de larga } \\
\text { duración? }\end{array}$ & Crisis y sanidad \\
\hline 18) & ) INTERNET: ¿Cuándo pedirá la disolución de ETA? & ETA \\
\hline 19) & $\begin{array}{l}\text { A los ciudadanos nos preocupa el gasto público, ¿piensan } \\
\text { bajarse o congelarse el sueldo para dar ejemplo en caso } \\
\text { de ganar las elecciones? }\end{array}$ & $\begin{array}{l}\text { Crisis y gasto } \\
\text { público y políticos }\end{array}$ \\
\hline 20) & $\begin{array}{l}\text { Todos los abertzales hemos dibujado en nuestra mente el } \\
\text { boceto de un estado vasco independiente en Europa, pero } \\
\text { hay pensadores de izquierda que afirman que pasaríamos } \\
\text { de estar bajo el dominio español al de otras potencias } \\
\text { incluso a caer bajo la órbita norteamericana, ¿qué les } \\
\text { respondería a los que hacen estos vaticinios? }\end{array}$ & Independencia \\
\hline \multicolumn{2}{|r|}{ 21) ¿Por qué no existe una ley de prioridad para la gente que } & Empleo \\
\hline
\end{tabular}




\begin{tabular}{|c|c|}
\hline ha nacido en Euskadi cuando surge un puesto de trabajo? & \\
\hline $\begin{array}{l}\text { 22) En un mundo tan global y digital como el actual y con el } \\
\text { particular en clave geográfico que tiene Euskadi, ¿qué } \\
\text { iniciativas tratará de promover para lograr una mayor } \\
\text { inserción de la sociedad vasca en el mundo de internet? }\end{array}$ & Globalización \\
\hline $\begin{array}{l}\text { 23) Creo que una nación no solo se alimenta de } \\
\text { nacionalismos sino que de un sentido identitario y para } \\
\text { ese sentido identitario es super importante la lengua y mi } \\
\text { pregunta va en el sentido de cuando tu si eres elegida } \\
\text { lehendakari ¿seguirás apostando por una Euskadi } \\
\text { bilingüe? }\end{array}$ & Lengua \\
\hline $\begin{array}{l}\text { 24) INTERNET: ¿Está usted a favor de legalizar la } \\
\text { prostitución y la droga como la marihuana? }\end{array}$ & $\begin{array}{l}\text { Droga y } \\
\text { prostitución }\end{array}$ \\
\hline $\begin{array}{l}\text { 25) ¿Qué planes hay para la educación, si es que van a seguir } \\
\text { subiendo las tasas de matrículas? }\end{array}$ & Crisis y educación \\
\hline $\begin{array}{l}\text { 26) En el Estado existe una deuda privada elevadísima que se } \\
\text { está filtrando a la pública, esta deuda es impagable y } \\
\text { lastra el consumo y la economía, ¿comparte mi análisis y } \\
\text { qué propone como solución? ¿Apoyaría un default o } \\
\text { quiebra de la economía controlada? }\end{array}$ & Crisis \\
\hline $\begin{array}{l}\text { 27) ¿Qué piensa hacer para la protección del medio ambiente } \\
\text { y patrimonio paisajístico, arquitectónico y cultural? }\end{array}$ & $\begin{array}{l}\text { Medioambiente y } \\
\text { cultura }\end{array}$ \\
\hline $\begin{array}{l}\text { 28) Le voy a pedir una pequeña reflexión sobre los políticos, } \\
\text { porque una cosa es hablar y otra cosa es hacer, ¿le parece } \\
\text { que los partidos políticos piensan y hacen más por ellos } \\
\text { mismos y por su poder que por las necesidades reales de } \\
\text { los ciudadanos de calle? }\end{array}$ & Políticos y política \\
\hline $\begin{array}{l}\text { 29) ¿Por qué un presidente con unos pocos años de presidente } \\
\text { tiene solucionada su vida con la renta vitalicia y un } \\
\text { ciudadano cotizando toda su vida, malvive? }\end{array}$ & Crisis y políticos \\
\hline $\begin{array}{l}\text { 30) INTERNET: ¿Por qué margina EH-Bildu a los presos de } \\
\text { la Vía Nanclares? }\end{array}$ & ETA \\
\hline $\begin{array}{l}\text { 31) ¿Si gobernaras en Euskadi, podrías evitar los recortes en } \\
\text { sanidad si estos recortes fueran necesarios en qué otra } \\
\text { área recortarías para poder mantener la sanidad como la } \\
\text { hemos conocido hasta ahora? }\end{array}$ & Crisis y sanidad \\
\hline $\begin{array}{l}\text { 32) ¿Qué le parece a Bildu que un país con una población de } \\
2 \text { millones } 200.000 \text { habitantes tenga que soportar } \\
\text { ayuntamientos, diputaciones, gobierno autonómico, } \\
\text { estatal y europeo, habría que recortar estas instituciones, } \\
\text { fusionar...? ¿Qué propone Bildu? }\end{array}$ & $\begin{array}{l}\text { Crisis e } \\
\text { instituciones }\end{array}$ \\
\hline $\begin{array}{l}\text { 33) Cómo propuesta reveladora Bildu incluye en su campaña } \\
\text { electoral la obligatoriedad del euskera y también el cierre } \\
\text { de ETB2, radio Victoria, radio Euskadi porque emiten en } \\
\text { castellano, como candidata a lehendakari por Bildu le } \\
\text { pregunto, ¿es usted consciente de que sus propuestas } \\
\text { toman un cariz cada vez más duro e impositivo y con ello } \\
\text { un parecido cada vez más asombroso con la dictadura de } \\
\text { Franco? }\end{array}$ & Lengua \\
\hline $\begin{array}{l}\text { 34) La base fundamental política de la formación que usted } \\
\text { representa es la independencia, ¿el día } 21 \text { de octubre si } \\
\text { ustedes ganan las elecciones seguirán apostando por esa } \\
\text { vía, si es así, me quiere usted explicar de qué y de quién } \\
\text { vamos a ser independientes y si estamos en Europa nos }\end{array}$ & Independencia \\
\hline
\end{tabular}




\begin{tabular}{|c|l}
\hline permitirán el concierto que tenemos? & \\
\hline 35) ¿Por qué hay corridas de toros en lugares donde gobierna & Toros \\
Bildu y en Donostia no? & \\
\hline
\end{tabular}

Preguntas del programa Euskadi pregunta a Laura Mintegi. Fuente: Elaboración propia

\subsection{Euzkadi pregunsta a Iñigo Urkullu}

El 4 de Octubre, en la recta final de la precampaña autonómica, le toca el turno a Iñigo Urkullu, candidato a lehendakari por el Partido Nacionalista Vasco.

El programa se estructura de la misma forma: 30 ciudadanos en plató que hacen sus preguntas, y 5 preguntas que llegan a través de internet. El candidato está de pié mirando de frente a su público, con una pierna un poco más adelantada que la otra para darle estabilidad y seguridad. En algunas ocasiones se mueve un poco suavemente hacia atrás. Responde con tranquilidad a todas las preguntas que le formulan. No parece dubitativo y es muy ágil en sus respuestas que son muy concretas. De hecho, la presentadora le dice en varias ocasiones que van muy bien de tiempo, "llevamos un ritmo trepidante", porque no utiliza los 3 minutos que le corresponden en cada turno. Es un programa que para el telespectador resulta ágil por la rapidez y precisión de las respuestas.

$\mathrm{Su}$ gesto facial es tranquilo, serio, pero agradable, solo esboza una ligera sonrisa en contadas ocasiones, por ejemplo después de una pregunta. Usa mucho las manos para dar fuerza a sus mensajes y enfatizar sus argumentos, pero lo hace de una forma suave, enlazando los dedos en ocasiones, enumerando con los dedos, abriendo los brazos y haciendo el gesto de acercar a la gente que está próxima a él. El tono de voz de Urkullu es bastante plano, no transmite grandes emociones.

A Iñigo Urkullu también le plantearon 35 preguntas (ver tabla 2): 


\section{Tabla 2}

\begin{tabular}{|c|c|c|}
\hline \multicolumn{2}{|r|}{ PREGUNTA } & \multirow{2}{*}{$\begin{array}{c}\text { TEMA } \\
\text { Crisis y política }\end{array}$} \\
\hline & $\begin{array}{l}\text { ¿Con la crisis que todos estamos padeciendo, serán claros } \\
\text { y apostarán por acotar el número de representantes } \\
\text { públicos en las instituciones, tanto diputaciones, } \\
\text { parlamentos como ayuntamientos? Porque yo creo que } \\
\text { tenemos la impresión los ciudadanos de que los errores de } \\
\text { nuestros representantes siempre los pagan los mismos. } \\
\text { Por eso quiero resaltar esta cuestión }\end{array}$ & \\
\hline 2) & $\begin{array}{l}\text { En una Europa unida el ánimo de independencia puede } \\
\text { dejar al País Vasco aislado frente a los futuros retos } \\
\text { comunes de los países que componen la actual Unión } \\
\text { Europea. ¿Cómo afrontaría su partido este aislamiento y } \\
\text { cómo explicaría a sus votantes las consecuencias que } \\
\text { estarían asociadas a una hipotética independencia de } \\
\text { Euskadi fuera de Europa, es más, expulsaría a los que no } \\
\text { tienen raíces vascas? }\end{array}$ & Independencia \\
\hline 3) & $\begin{array}{l}\text { El próximo } 21 \text { de Octubre los ciudadanos van a emitir su } \\
\text { voto eligiendo libremente así a quien quieren que } \\
\text { gobierne y les represente en el Parlamento Vasco. ¿Piensa } \\
\text { usted que debería gobernar la fuerza o la formulación } \\
\text { política o coalición más votada respetando así la voluntad } \\
\text { expresada por la mayoría de los votantes? }\end{array}$ & Pacto político \\
\hline 4) & $\begin{array}{l}\text { Sabiendo que una gran infraestructura como es el tren de } \\
\text { alta velocidad supone un gasto enorme en un momento } \\
\text { como el actual, que su construcción no ha sido consultada } \\
\text { a las y los ciudadanos de aquí y que apenas vamos a } \\
\text { poder utilizarlo dado su precio, ¿cómo es que su partido } \\
\text { apuesta por ella y no por una renovación, una mejora de } \\
\text { las infraestructuras que ya existen y que además unen a } \\
\text { los pueblos de Euskal Herria y no solo las } 3 \text { capitales? }\end{array}$ & Crisis y transportes \\
\hline 5) & $\begin{array}{l}\text { ¿La independencia de Euskal Herria puede ser una } \\
\text { medida para salir de la crisis? }\end{array}$ & $\begin{array}{l}\text { Independencia y } \\
\text { crisis }\end{array}$ \\
\hline 6) & $\begin{array}{l}\text { INTERNET: ¿Por qué el PNV no apoya una moción de } \\
\text { censura contra Bildu en Guipuzcoa? }\end{array}$ & Política \\
\hline 7) & $\begin{array}{l}\text { ¿Me gustaría saber si usted considera la lengua y la } \\
\text { literatura en castellano hecha por autores vascos como } \\
\text { parte integrante del acervo cultural vasco y por tanto } \\
\text { como un medio de expresión válido y legítimo de ideas, } \\
\text { de pensamiento y de culturas vascas? }\end{array}$ & Lengua \\
\hline 8) & $\begin{array}{l}\text { ¿Cuándo es la última vez que ha acudido a un hospital } \\
\text { público? ¿Contempla, en el caso de que gane las } \\
\text { elecciones, la aplicación del cheque sociosanitario para el } \\
\text { cuidado de nuestros mayores y nuestros dependientes de } \\
\text { forma que aflore la economía sumergida y que mejore la } \\
\text { calidad del los cuidados? }\end{array}$ & Crisis y sanidad \\
\hline 9) & $\begin{array}{l}\text { ¿Si como objetivo del PNV está la independencia, en qué } \\
\text { situación podrían quedar los pensionistas? El País Vasco } \\
\text { por si solo no parece que pudiera sostener en las mismas } \\
\text { condiciones a los jubilados. }\end{array}$ & $\begin{array}{l}\text { Independencia y } \\
\text { crisis }\end{array}$ \\
\hline & $\begin{array}{l}\text { ¿Piensan imitar a Izquierda Unida o a EH-Bildu para } \\
\text { tratar de sacar los excedentes de vivienda que los bancos } \\
\text { intervenidos tienen, para uso social o alquileres sociales o }\end{array}$ & Crisis y vivienda \\
\hline
\end{tabular}




\begin{tabular}{|c|c|}
\hline algo por el estilo? & \\
\hline $\begin{array}{l}\text { 11) Usted aprobó prácticamente todas las medidas } \\
\text { económicas de Zapatero y visto cómo ha quedado el país, } \\
\text { se arrepiente de ello? }\end{array}$ & Crisis \\
\hline $\begin{array}{l}\text { 12) INTERNET: He escuchado en varias ocasiones decir que } \\
\text { el PNV en lo social es igual de conservador o de derechas } \\
\text { que el Partido Popular, ¿me gustaría preguntarle al } \\
\text { candidato Urkullu si el PNV apoyaría la eliminación de } \\
\text { simbología y actos religiosos en la vida política y civil, } \\
\text { algo a lo que el Partido Popular se opone, y también si el } \\
\text { PNV apoya el derecho actual de la mujer a interrumpir } \\
\text { voluntariamente el embarazo y de una pareja homosexual } \\
\text { a formar un matrimonio? }\end{array}$ & $\begin{array}{l}\text { Simbología } \\
\text { religiosa, } \\
\text { matrimonio } \\
\text { homosexual y } \\
\text { aborto }\end{array}$ \\
\hline $\begin{array}{l}\text { 13) Me gustaría hacer hincapié en el futuro que nos espera a } \\
\text { los ciudadanos de la Rioja alavesa de cara a nuestros } \\
\text { productos. Como sabe, muchas personas de esta zona } \\
\text { vivimos del monocultivo y los últimos años están siendo } \\
\text { difíciles. Me gustaría que se acordaran también de } \\
\text { nuestras zonas rurales como esta no solo para los votos. } \\
\text { ¿Qué medidas especiales plantean? }\end{array}$ & Crisis \\
\hline $\begin{array}{l}\text { 14) ¿Qué va a hacer su partido respecto a la liberalización de } \\
\text { los horarios comerciales para que podamos conciliar } \\
\text { trabajo y vida familiar? }\end{array}$ & $\begin{array}{l}\text { Liberalización de } \\
\text { horarios } \\
\text { comerciales }\end{array}$ \\
\hline $\begin{array}{l}\text { 15) Mencionaba usted al principio apretarse el cinturón, } \\
\text { cuando hay personas que están mencionando un } \\
\text { aplicación de un copago o un supuesto copago, ¿es usted } \\
\text { partidario, por cuánto tiempo, en qué servicios? }\end{array}$ & Crisis y sanidad \\
\hline $\begin{array}{l}\text { 16) ¿Qué hará su partido con los casos de exclusión social en } \\
\text { el combate contra la pobreza y con las ayudas sociales, } \\
\text { por ejemplo renta básica...? }\end{array}$ & $\begin{array}{l}\text { Crisis y } \\
\text { desigualdades } \\
\text { sociales }\end{array}$ \\
\hline $\begin{array}{l}\text { 17) ¿Qué va a hacer el PNV para garantizar las conquistas } \\
\text { sociales que tanto nos costó tener y que gracias a este } \\
\text { sistema capitalista dichas conquistas las perdemos a pasos } \\
\text { agigantados? ¿Desobedecería usted las medidas de } \\
\text { recorte injustas? }\end{array}$ & $\begin{array}{l}\text { Crisis y } \\
\text { desigualdades } \\
\text { sociales }\end{array}$ \\
\hline $\begin{array}{l}\text { 18) INTERNET: ¿Cree usted que el Estatuto de Gernika está } \\
\text { agotado? Y, si es así, ¿considera usted que se deben dar } \\
\text { pasos esta legislatura para hacer de Euskadi una realidad } \\
\text { nacional en Europa? }\end{array}$ & $\begin{array}{l}\text { Estatuto de } \\
\text { Gernika }\end{array}$ \\
\hline $\begin{array}{l}\text { 19) ¿Qué piensa hacer para que cada uno pague los impuestos } \\
\text { que le corresponden. Porque los que tenemos una nómina } \\
\text { estamos controlados pero los demás no. Quitará las } \\
\text { declaraciones por módulos y se controlarán más las } \\
\text { profesiones liberales ya que Hacienda cada vez que hace } \\
\text { inspecciones pilla a bastantes y se recauda más, y } \\
\text { controlarán más los ingresos mínimos de garantía para } \\
\text { evitar que ciertos grupos de hasta } 3 \text { generaciones vivan de } \\
\text { ellas y no trabajen o las familias monoparentales } \\
\text { voluntarias tengan los ingresos garantizados hasta la } \\
\text { mayoría de edad del niño? }\end{array}$ & Impuestos \\
\hline $\begin{array}{l}\text { 20) La sanidad, la educación y la acción social son pilares } \\
\text { fundamentales desde siempre en nuestra sociedad, ¿existe } \\
\text { margen de maniobra para que estos pilares no sufran } \\
\text { recortes? }\end{array}$ & $\begin{array}{l}\text { Crisis y bienestar } \\
\text { social }\end{array}$ \\
\hline
\end{tabular}




\begin{tabular}{|c|c|}
\hline $\begin{array}{l}\text { 21) Ante un escenario de recesión profunda donde cada vez } \\
\text { hay más presiones para que los recursos públicos se } \\
\text { utilicen de una manera más eficiente, ¿cree que el actual } \\
\text { sistema político de convivencia entre el Gobierno vasco y } \\
\text { las diputaciones presentan duplicidades que podrían } \\
\text { evitarse y así destinar esos recursos para otras partidas } \\
\text { más sensibles? }\end{array}$ & $\begin{array}{l}\text { Crisis y gasto } \\
\text { público }\end{array}$ \\
\hline $\begin{array}{l}\text { 22) En los mítines políticos oigo siempre decir que el } \\
\text { pequeño empresario, autónomo son los que crean el tejido } \\
\text { industrial y luego cuando llega el momento de ayudar } \\
\text { ayudan a las grandes empresas que se llevan las } \\
\text { subvenciones, les dan créditos blandos, y de estas muchas } \\
\text { dejan de pagar la Seguridad Social, los trabajadores } \\
\text { tienen derecho a paro como es normal. Con lo } \\
\text { importantes que dicen que somos las pequeñas empresas } \\
\text { y autónomos, ¿quién nos ayuda a nosotros, estamos en } \\
\text { tierra de nadie, por qué no se crean por parte del gobierno } \\
\text { vasco créditos blandos en una situación tan difícil como } \\
\text { la actual como se hizo en las inundaciones del año } 83 ?\end{array}$ & Crisis y autónomos \\
\hline $\begin{array}{l}\text { 23) ¿Está usted a favor de que exijan el euskera hoy en día en } \\
\text { todos los puestos de trabajo? }\end{array}$ & Lengua \\
\hline $\begin{array}{l}\text { 24) INTERNET: Parece evidente que una Euskal Herria } \\
\text { independiente con } 7 \text { territorios no es viable vistas las } \\
\text { mayorías existentes, ¿estaría a favor de una partición de } \\
\text { euskal herria respecto a la independencia y a aceptar, si se } \\
\text { da el caso, una independencia de los } 3 \text { territorios de la } \\
\text { actual Comunidad Autónoma vasca? }\end{array}$ & Independencia \\
\hline $\begin{array}{l}\text { 25) Partiendo de la base de que la educación es la mejor vía } \\
\text { para paliar la desigualdad y prevenir el fracaso escolar y } \\
\text { el abandono escolar, ¿no cree usted que el mayor } \\
\text { esfuerzo presupuestario debe hacerse en educación } \\
\text { pública y en programas que luchan contra el abandono } \\
\text { temprano de la escuela y el riesgo de exclusión social en } \\
\text { programas antes llamados en la Comunidad Autónoma } \\
\text { como la iniciación profesional, luego llamados CIPs y } \\
\text { hoy en día programas de cualificación iniciales. Qué } \\
\text { propuestas tiene usted en este ámbito? }\end{array}$ & Crisis y educación \\
\hline $\begin{array}{l}\text { 26) La resolución del Parlamento europeo de } 24 \text { de mayo de } \\
2012 \text { habla de eliminar casi por completo la producción } \\
\text { de deshechos no reciclables ni compostables, prohibir los } \\
\text { vertederos y eliminar la incineración de residuos } \\
\text { reciclables y compostables todo para el } 2020 \text {. Teniendo } \\
\text { en cuenta que existen en la comunidad autónoma vasca } \\
\text { una incineradora con capacidad para quemar } 240.000 \\
\text { toneladas anuales de basura y hay en proyecto otra en } \\
\text { Zubieta para } 220.000 \text { toneladas. ¿Cree usted que seremos } \\
\text { capaces de producir } 210 \text { quilos por persona y año de } \\
\text { residuos no reciclables ni compostables o habrá que } \\
\text { importar basura, ya lo ha hecho el PP en Mallorca, para } \\
\text { bajar las tasas? }\end{array}$ & Reciclaje \\
\hline $\begin{array}{l}\text { 27) Esta noche ya lo ha defendido más de una vez, Euskadi } \\
\text { nación en Europa, bien, el President catalán Artur Mas ha } \\
\text { dicho que va a convocar un referéndum de } \\
\text { autodeterminación independientemente de lo que diga } \\
\text { Madrid, ¿se compromete usted a hacer lo mismo en }\end{array}$ & Independencia \\
\hline
\end{tabular}




\begin{tabular}{|c|c|}
\hline Euskal Herria en el caso de que llegue a ser lehendakari? & \\
\hline $\begin{array}{l}\text { 28) Recientemente en el Congreso de Madrid el PNV votaba } \\
\text { a favor de algunas enmiendas para dar subvenciones } \\
\text { multimillonarias a la industria armamentística porque, } \\
\text { palabras textuales "la investigación en la industria } \\
\text { armamentística redunda en la sociedad civil", ¿podría } \\
\text { explicarnos que piensa sobre la industria armamentística? }\end{array}$ & Armas \\
\hline $\begin{array}{l}\text { 29) La sociedad vasca está harta de oír que no hay más } \\
\text { solución a la crisis que los recortes de sueldo y servicios } \\
\text { públicos. ¿Si gana el PNV afrontará el severo fraude } \\
\text { físcal y gravará en su justa medida a los ricos? }\end{array}$ & $\begin{array}{l}\text { Crisis y bienestar } \\
\text { social }\end{array}$ \\
\hline $\begin{array}{l}\text { 30) INTERNET: Qué es prioritario para usted, mantener las } \\
\text { tradiciones donde año tras año en nuestros pueblos y } \\
\text { barrios se maltrata y tortura animales indefensos para el } \\
\text { deleite y disfrute del personal tales como las corridas de } \\
\text { toros, arrastre de bueyes, carreras de burros y demás, o } \\
\text { preferiría que los animales no formaran parte de nuestros } \\
\text { festejos? Si es así, promovería alguna ley para acabar con } \\
\text { estas macabras costumbres? }\end{array}$ & Toros \\
\hline $\begin{array}{l}\text { 31) ¿Después de polémicas sobre la sanidad a los inmigrantes } \\
\text { se nos garantizará la atención o tendremos que pagarla? } \\
\text { ¿En su programa electoral colocará de forma clara el } \\
\text { compromiso de regular los lugares de culto para evitar } \\
\text { situaciones complicadas con los vecinos? }\end{array}$ & $\begin{array}{l}\text { Crisis y sanidas e } \\
\text { inmigración }\end{array}$ \\
\hline $\begin{array}{l}\text { 32) ¿Cuál sería su primera opción ante posibles alianzas para } \\
\text { formar gobierno? }\end{array}$ & Pacto \\
\hline $\begin{array}{l}\text { 33) A diferencia de nuestros gobernantes forales han dicho } \\
\text { ustedes que van a elaborar un plan anticrisis en } \\
\text { Guipuzcoa, ¿ para cuándo lo van a hacer? }\end{array}$ & Crisis \\
\hline $\begin{array}{l}\text { 34) ¿Vería usted con buenos ojos la abolición de la } \\
\text { monarquía? ¿Qué opina usted sobre esta institución? }\end{array}$ & Monarquía \\
\hline $\begin{array}{l}\text { 35) Teniendo en cuenta la nueva situación política en Euskal } \\
\text { Herria, ¿qué va a hacer usted para poner fin a la } \\
\text { dispersión de presos vascos, teniendo en cuenta que su } \\
\text { partido ha sido parte protagonista. Y van a hacer } \\
\text { autocrítica del pasado como ustedes piden a otros que lo } \\
\text { hagan? }\end{array}$ & Presos vascos-ETA \\
\hline
\end{tabular}

Preguntas del programa Euskadi pregunta a Iñigo Urkullu. Fuente: Elaboración propia

\section{Análisis de los temas de interñes de la ciudadanía vasca}

Una vez recogidas todas las preguntas realizadas por los ciudadanos participantes en el programa Euskadi pregunta el siguiente paso es analizar la relación existente entre esos temas y los que, según el Euskobarómetro son los que más preocupan a la ciudadanía vasca. 
El primero de ellos, según este sondeo de opinión, es el empleo, que preocupa a un $56 \%$ de los encuestados, unido de forma indivisible a la situación de crisis que vive el país que es la segunda gran preocupación de la ciudadanía vasca según el $20 \%$ de los participantes en el sondeo.

La preocupación por la crisis se une al pesimismo ante el escenario económico español con un máximo histórico del $89 \%$ de los encuestados, dejando como insignificante el $1 \%$ de personas que siguen siendo optimistas ante la situación económica actual.

Pues bien, de las 70 preguntas formuladas en los dos programas analizados, 32, es decir, casi un $50 \%$, se refieren directamente a la crisis, relacionándola en ocasiones con la preocupación por el bienestar ciudadano y el recorte de derechos en la sanidad o la educación fundamentalmente.

Esto es significativo porque las desigualdades sociales y el bienestar son la tercera preocupación de la ciudadanía vasca según el 13\% de los encuestados.

La situación política preocupa solo a un 4\%, y así se refleja también en el programa Euskadi pregunta, donde las preguntas relacionadas con la política, 7 preguntas en total, se relacionan o con el gasto público y la reducción de la administración, enlazando con la crisis, o con las posibilidades de pacto de los candidatos y sus preferencias.

En este sentido destacamos el dato que recoge el sondeo y que indica que la ciudadanía vasca suspende a su clase política.

Otro de los temas recurrentes en el programa es el de la independencia, dedican 7 preguntas a este tema, y esto también aparece reflejado en el sondeo.

Según el Euskobarómetro un 33\% de la ciudadanía manifiesta tener grandes deseos de independencia, aún así la mayoría, el 54\%, dicen tener pocos o ninguno.

Otro de los aspectos analizados en este sentido son las consecuencias que tendría una inminente independencia en la calidad de la ciudadanía. Un $31 \%$ piensa que viviría mejor, un $28 \%$ peor y un $25 \%$ no sabe que decir. Estos porcentajes son interesantes porque en las preguntas sobre la posibilidad de una Euskadi independiente se plantean también estos temores.

Otra preocupación que se repite en el programa Euskadi pregunta y que también recoge el barómetro vasco, es la de la lengua. Coincide el planteamiento con los resultados del sondeo, donde el $64 \%$ de los encuestados reclama de las instituciones públicas una política lingüística que fomente el aprendizaje y el uso del euskera de forma progresiva y respetuosa, es decir, sin imposiciones, ni demasiadas prisas.

En las preguntas realizadas por los ciudadanos se quiere conocer la opinión de los candidatos ante el bilingüismo y la imposición. En este sentido ambos candidatos se muestran partidarios de evitar la imposición del euskera y favorecer su implantación progresiva. 


\section{Conclusiones}

Partimos de la hipótesis de que la persona que hace la pregunta en la televisión lo hace interesándose por temas que le preocupan personalmente o que son de interés general para el conjunto de la ciudadanía vasca. Teniendo eso en cuenta, esos temas deben coincidir con los que aparecen reflejados en el estudio de opinión.

Con el análisis realizado se confirma que es así. Las principales preocupaciones de los ciudadanos vascos, que aparecen como tal en el euskobarómetro, también concentran la mayor parte de las preguntas realizadas a los candidatos durante el desarrollo del programa.

El empleo y la crisis, que interesan a casi el 50\% de los participantes en el programa de televisión y es la principal preocupación de la ciudadanía según el sondeo, o la lengua, con las múltiples variantes personales que puedan tener, son efectivamente temas coincidentes en la mayoría de los ciudadanos y ciudadanas tal y como refleja la encuesta y posteriormente el programa

Por lo tanto podemos concluir que tanto el Euskobarómetro como el programa Euskadi pregunta coinciden en gran medida al presentar las principales preocupaciones de los vascos y vascas.

\section{Bibliografía}

BARNÉS, Jorge Santiago (2010): El candidato ante los medios: telegenia e imagen política. Madrid, Editorial Fragua

CANEL, María José (2006): Comunicación Política. Una guía para su estudio y práctica. Madrid, Editorial Tecnos (Grupo Anaya, S.A.)

DEL REY MORATÓ, Javier (2008): Comunicación Política, Internet y Campañas Electorales. De la teledemocracia a la ciberdemocracia. Madrid, Editorial Tecnos (Grupo Anaya, S.A.)

IGARTUA PEROSANZ, Juan José (2006): Métodos cuantitativos de investigación en comunicación. Barcelona, Editorial Bosch, S.A.

KRIPPENDORFF, Klaus (1990): Metodología de análisis de contenido. Teoría y práctica. Barcelona, Ediciones Paidós Ibérica, S.A.

SABUCEDO CAMESELLE, José Manuel (1996): Psicología Política. Madrid, Editorial Síntesis, S.A.

VAN DIJK, T. (2009): Análisis del discurso. Discurso y poder. Barcelona, Editorial Gedisa, S.A.

Euskobarómetro de mayo de 2012 


\section{La autora}

Susana Pardiñas Iglesias es licenciada en Periodismo por la Universidad Carlos III de Madrid y Doctoranda en el ámbito del Análisis del Discurso por la Universidad Complutense de Madrid.

Ejerció el periodismo activo en medios como la Televisión de Galicia en los que aprendió las bases de la profesión y su plasmación en la práctica. Posteriormente trabajó en Gabinetes de prensa institucionales, conociendo así de primera mano el trabajo periodístico desde el otro "lado de la barrera" y pudiendo comprobar lo diferente que se ve el trabajo de unos y otros dependiendo del lugar donde se trabaje, y la importancia de la objetividad como clave en su carrera.

Más tarde decidió centrarse en su carrera académica y se marchó a Madrid donde continuó con sus estudios de doctorado en Periodismo.

En la actualidad compagina su investigación centrada en el análisis del discurso político y las campañas electorales, con su vocación docente relacionada siempre con la comunicación y las TIC. 